\title{
Principles of Clinical Ethics and Their Application to Practice
}

\author{
Basil Varkey \\ The Medical College of Wisconsin, Milwaukee, WI, USA
}

\section{Highlights of the Study}

- Main principles of ethics, that is beneficence, nonmaleficence, autonomy, and justice, are discussed.

- Autonomy is the basis for informed consent, truth-telling, and confidentiality.

- A model to resolve conflicts when ethical principles collide is presented.

- Cases that highlight ethical issues and their resolution are presented.

- A patient care model that integrates ethics, professionalism, and cognitive and technical expertise is shown.

\section{Keywords}

Ethics - Confidentiality · Autonomy · Informed consent .

Professionalism · Integrated patient care model

\section{Abstract}

An overview of ethics and clinical ethics is presented in this review. The 4 main ethical principles, that is beneficence, nonmaleficence, autonomy, and justice, are defined and explained. Informed consent, truth-telling, and confidentiality spring from the principle of autonomy, and each of them is discussed. In patient care situations, not infrequently, there are conflicts between ethical principles (especially between beneficence and autonomy). A four-pronged systematic approach to ethical problem-solving and several illustrative cases of conflicts are presented. Comments following the cases highlight the ethical principles involved and clarify the resolution of these conflicts. A model for patient care, with caring as its central element, that integrates ethical aspects (intertwined with professionalism) with clinical and technical expertise desired of a physician is illustrated.

(c) 2020 The Author(s)

Published by S. Karger AG, Basel

karger@karger.com

www.karger.com/mpp

Karger ${ }^{\prime \prime} \div$

GOPEN ACCESS
(C) 2020 The Author(s)

Published by S. Karger AG, Basel

This is an Open Access article licensed under the Creative Commons Attribution-NonCommercial-4.0 International License (CC BY-NC) (http://www.karger.com/Services/OpenAccessLicense), applicable to the online version of the article only. Usage and distribution for commercial purposes requires written permission.

\section{Introduction}

A defining responsibility of a practicing physician is to make decisions on patient care in different settings. These decisions involve more than selecting the appropriate treatment or intervention.

Ethics is an inherent and inseparable part of clinical medicine [1] as the physician has an ethical obligation (i) to benefit the patient, (ii) to avoid or minimize harm, and to (iii) respect the values and preferences of the patient. Are physicians equipped to fulfill this ethical obligation and can their ethical skills be improved? A goal-oriented educational program [2] (Table 1) has been shown to improve learner awareness, attitudes, knowledge, moral reasoning, and confidence $[3,4]$.

\section{Ethics, Morality, and Professional Standards}

Ethics is a broad term that covers the study of the nature of morals and the specific moral choices to be made. Normative ethics attempts to answer the question, "Which general moral norms for the guidance and evalu- 
Table 1. Goals of ethics education

- To appreciate the ethical dimensions of patient care

- To understand ethical principles of medical profession

- To have competence in core ethical behavioral skills

(Obtaining informed consent, assessing decision-making capacity, discussing resuscitation status and use of lifesustaining treatments, advanced care planning, breaking bad news and effective communication)

- To know the commonly encountered ethical issues in general and in one's specialty

- To have competence in analyzing and resolving ethical problems

- To appreciate cultural diversity and its impact on ethics

ation of conduct should we accept, and why?" [5]. Some moral norms for right conduct are common to human kind as they transcend cultures, regions, religions, and other group identities and constitute common morality (e.g., not to kill, or harm, or cause suffering to others, not to steal, not to punish the innocent, to be truthful, to obey the law, to nurture the young and dependent, to help the suffering, and rescue those in danger). Particular morality refers to norms that bind groups because of their culture, religion, profession and include responsibilities, ideals, professional standards, and so on. A pertinent example of particular morality is the physician's "accepted role" to provide competent and trustworthy service to their patients. To reduce the vagueness of "accepted role," physician organizations (local, state, and national) have codified their standards. However, complying with these standards, it should be understood, may not always fulfill the moral norms as the codes have "often appeared to protect the profession's interests more than to offer a broad and impartial moral viewpoint or to address issues of importance to patients and society" [6].

\section{Bioethics and Clinical (Medical) Ethics}

A number of deplorable abuses of human subjects in research, medical interventions without informed consent, experimentation in concentration camps in World War II, along with salutary advances in medicine and medical technology and societal changes, led to the rapid evolution of bioethics from one concerned about professional conduct and codes to its present status with an extensive scope that includes research ethics, public health ethics, organizational ethics, and clinical ethics.
Hereafter, the abbreviated term, ethics, will be used as I discuss the principles of clinical ethics and their application to clinical practice.

\section{The Fundamental Principles of Ethics}

Beneficence, nonmaleficence, autonomy, and justice constitute the 4 principles of ethics. The first 2 can be traced back to the time of Hippocrates "to help and do no harm," while the latter 2 evolved later. Thus, in Percival's book on ethics in early 1800s, the importance of keeping the patient's best interest as a goal is stressed, while autonomy and justice were not discussed. However, with the passage of time, both autonomy and justice gained acceptance as important principles of ethics. In modern times, Beauchamp and Childress' book on Principles of Biomedical Ethics is a classic for its exposition of these 4 principles [5] and their application, while also discussing alternative approaches.

\section{Beneficence}

The principle of beneficence is the obligation of physician to act for the benefit of the patient and supports a number of moral rules to protect and defend the right of others, prevent harm, remove conditions that will cause harm, help persons with disabilities, and rescue persons in danger. It is worth emphasizing that, in distinction to nonmaleficence, the language here is one of positive requirements. The principle calls for not just avoiding harm, but also to benefit patients and to promote their welfare. While physicians' beneficence conforms to moral rules, and is altruistic, it is also true that in many instances it can be considered a payback for the debt to society for education (often subsidized by governments), ranks and privileges, and to the patients themselves (learning and research).

\section{Nonmaleficence}

Nonmaleficence is the obligation of a physician not to harm the patient. This simply stated principle supports several moral rules - do not kill, do not cause pain or suffering, do not incapacitate, do not cause offense, and do not deprive others of the goods of life. The practical application of nonmaleficence is for the physician to weigh the benefits against burdens of all interventions and treatments, to eschew those that are inappropriately burdensome, and to choose the best course of action for the patient. This is particularly important and pertinent in difficult end-of-life care decisions on withholding and 
withdrawing life-sustaining treatment, medically administered nutrition and hydration, and in pain and other symptom control. A physician's obligation and intention to relieve the suffering (e.g., refractory pain or dyspnea) of a patient by the use of appropriate drugs including opioids override the foreseen but unintended harmful effects or outcome (doctrine of double effect) $[7,8]$.

\section{Autonomy}

The philosophical underpinning for autonomy, as interpreted by philosophers Immanuel Kant (1724-1804) and John Stuart Mill (1806-1873), and accepted as an ethical principle, is that all persons have intrinsic and unconditional worth, and therefore, should have the power to make rational decisions and moral choices, and each should be allowed to exercise his or her capacity for selfdetermination [9]. This ethical principle was affirmed in a court decision by Justice Cardozo in 1914 with the epigrammatic dictum, "Every human being of adult years and sound mind has a right to determine what shall be done with his own body" [10].

Autonomy, as is true for all 4 principles, needs to be weighed against competing moral principles, and in some instances may be overridden; an obvious example would be if the autonomous action of a patient causes harm to another person(s). The principle of autonomy does not extend to persons who lack the capacity (competence) to act autonomously; examples include infants and children and incompetence due to developmental, mental or physical disorder. Health-care institutions and state governments in the US have policies and procedures to assess incompetence. However, a rigid distinction between incapacity to make health-care decisions (assessed by health professionals) and incompetence (determined by court of law) is not of practical use, as a clinician's determination of a patient's lack of decision-making capacity based on physical or mental disorder has the same practical consequences as a legal determination of incompetence [11].

Detractors of the principle of autonomy question the focus on the individual and propose a broader concept of relational autonomy (shaped by social relationships and complex determinants such as gender, ethnicity and culture) [12]. Even in an advanced western country such as United States, the culture being inhomogeneous, some minority populations hold views different from that of the majority white population in need for full disclosure, and in decisions about life support (preferring a familycentered approach) [13].

Resistance to the principle of patient autonomy and its derivatives (informed consent, truth-telling) in non- western cultures is not unexpected. In countries with ancient civilizations, rooted beliefs and traditions, the practice of paternalism (this term will be used in this article, as it is well-entrenched in ethics literature, although parentalism is the proper term) by physicians emanates mostly from beneficence. However, culture (a composite of the customary beliefs, social forms, and material traits of a racial, religious or social group) is not static and autonomous, and changes with other trends over passing years. It is presumptuous to assume that the patterns and roles in physician-patient relationships that have been in place for a half a century and more still hold true. Therefore, a critical examination of paternalistic medical practice is needed for reasons that include technological and economic progress, improved educational and socioeconomic status of the populace, globalization, and societal movement towards emphasis on the patient as an individual, than as a member of a group. This needed examination can be accomplished by research that includes well-structured surveys on demographics, patient preferences on informed consent, truth-telling, and role in decision-making.

Respecting the principle of autonomy obliges the physician to disclose medical information and treatment options that are necessary for the patient to exercise selfdetermination and supports informed consent, truthtelling, and confidentiality.

\section{Informed Consent}

The requirements of an informed consent for a medical or surgical procedure, or for research, are that the patient or subject (i) must be competent to understand and decide, (ii) receives a full disclosure, (iii) comprehends the disclosure, (iv) acts voluntarily, and (v) consents to the proposed action.

The universal applicability of these requirements, rooted and developed in western culture, has met with some resistance and a suggestion to craft a set of requirements that accommodate the cultural mores of other countries [14]. In response and in vigorous defense of the 5 requirements of informed consent, Angell wrote, "There must be a core of human rights that we would wish to see honored universally, despite variations in their superficial aspects ... The forces of local custom or local law cannot justify abuses of certain fundamental rights, and the right of self-determination on which the doctrine of informed consent is based, is one of them" [15].

As competence is the first of the requirements for informed consent, one should know how to detect incompetence. Standards (used singly or in combination) that 
are generally accepted for determining incompetence are based on the patient's inability to state a preference or choice, inability to understand one's situation and its consequences, and inability to reason through a consequential life decision [16].

In a previously autonomous, but presently incompetent patient, his/her previously expressed preferences (i.e., prior autonomous judgments) are to be respected [17]. Incompetent (non-autonomous) patients and previously competent (autonomous), but presently incompetent patients would need a surrogate decision-maker. In a non-autonomous patient, the surrogate can use either a substituted judgment standard (i.e., what the patient would wish in this circumstance and not what the surrogate would wish), or a best interests standard (i.e., what would bring the highest net benefit to the patient by weighing risks and benefits). Snyder and Sulmasy [18], in their thoughtful article, provide a practical and useful option when the surrogate is uncertain of the patient's preference(s), or when patient's preferences have not kept abreast of scientific advances. They suggest the surrogate use "substituted interests," that is, the patient's authentic values and interests, to base the decision.

\section{Truth-Telling}

Truth-telling is a vital component in a physician-patient relationship; without this component, the physician loses the trust of the patient. An autonomous patient has not only the right to know (disclosure) of his/her diagnosis and prognosis, but also has the option to forgo this disclosure. However, the physician must know which of these 2 options the patient prefers.

In the United States, full disclosure to the patient, however grave the disease is, is the norm now, but was not so in the past. Significant resistance to full disclosure was highly prevalent in the US, but a marked shift has occurred in physicians' attitudes on this. In 1961, 88\% of physicians surveyed indicated their preference to avoid disclosing a diagnosis [19]; in 1979, however, $98 \%$ of surveyed physicians favored it [20]. This marked shift is attributable to many factors that include - with no order of importance implied - educational and socioeconomic progress, increased accountability to society, and awareness of previous clinical and research transgressions by the profession.

Importantly, surveys in the US show that patients with cancer and other diseases wish to have been fully informed of their diagnoses and prognoses. Providing full information, with tact and sensitivity, to patients who want to know should be the standard. The sad conse- quences of not telling the truth regarding a cancer include depriving the patient of an opportunity for completion of important life-tasks: giving advice to, and taking leave of loved ones, putting financial affairs in order, including division of assets, reconciling with estranged family members and friends, attaining spiritual order by reflection, prayer, rituals, and religious sacraments [21, 22].

In contrast to the US, full disclosure to the patient is highly variable in other countries [23]. A continuing pattern in non-western societies is for the physician to disclose the information to the family and not to the patient. The likely reasons for resistance of physicians to convey bad news are concern that it may cause anxiety and loss of hope, some uncertainty on the outcome, or belief that the patient would not be able to understand the information or may not want to know. However, this does not have to be a binary choice, as careful understanding of the principle of autonomy reveals that autonomous choice is a right of a patient, and the patient, in exercising this right, may authorize a family member or members to make decisions for him/her.

\section{Confidentiality}

Physicians are obligated not to disclose confidential information given by a patient to another party without the patient's authorization. An obvious exception (with implied patient authorization) is the sharing necessary of medical information for the care of the patient from the primary physician to consultants and other health-care teams. In the present-day modern hospitals with multiple points of tests and consultants, and the use of electronic medical records, there has been an erosion of confidentiality. However, individual physicians must exercise discipline in not discussing patient specifics with their family members or in social gatherings [24] and social media. There are some noteworthy exceptions to patient confidentiality. These include, among others, legally required reporting of gunshot wounds and sexually transmitted diseases and exceptional situations that may cause major harm to another (e.g., epidemics of infectious diseases, partner notification in HIV disease, relative notification of certain genetic risks, etc.).

\section{Justice}

Justice is generally interpreted as fair, equitable, and appropriate treatment of persons. Of the several categories of justice, the one that is most pertinent to clinical ethics is distributive justice. Distributive justice refers to the fair, equitable, and appropriate distribution of healthcare resources determined by justified norms that struc- 
ture the terms of social cooperation [25]. How can this be accomplished? There are different valid principles of distributive justice. These are distribution to each person (i) an equal share, (ii) according to need, (iii) according to effort, (iv) according to contribution, (v) according to merit, and (vi) according to free-market exchanges. Each principle is not exclusive, and can be, and are often combined in application. It is easy to see the difficulty in choosing, balancing, and refining these principles to form a coherent and workable solution to distribute medical resources.

Although this weighty health-care policy discussion exceeds the scope of this review, a few examples on issues of distributive justice encountered in hospital and office practice need to be mentioned. These include allotment of scarce resources (equipment, tests, medications, organ transplants), care of uninsured patients, and allotment of time for outpatient visits (equal time for every patient? based on need or complexity? based on social and or economic status?). Difficult as it may be, and despite the many constraining forces, physicians must accept the requirement of fairness contained in this principle [26]. Fairness to the patient assumes a role of primary importance when there are conflicts of interests. A flagrant example of violation of this principle would be when a particular option of treatment is chosen over others, or an expensive drug is chosen over an equally effective but less expensive one because it benefits the physician, financially, or otherwise.

\section{Conflicts between Principles}

Each one of the 4 principles of ethics is to be taken as a prima facie obligation that must be fulfilled, unless it conflicts, in a specific instance, with another principle. When faced with such a conflict, the physician has to determine the actual obligation to the patient by examining the respective weights of the competing prima facie obligations based on both content and context. Consider an example of a conflict that has an easy resolution: a patient in shock treated with urgent fluid-resuscitation and the placement of an indwelling intravenous catheter caused pain and swelling. Here the principle of beneficence overrides that of nonmaleficence. Many of the conflicts that physicians face, however, are much more complex and difficult. Consider a competent patient's refusal of a potentially life-saving intervention (e.g., instituting mechanical ventilation) or request for a potentially life-ending action (e.g., withdrawing mechanical ventilation).
Nowhere in the arena of ethical decision-making is conflict as pronounced as when the principles of beneficence and autonomy collide.

Beneficence has enjoyed a historical role in the traditional practice of medicine. However, giving it primacy over patient autonomy is paternalism that makes a physician-patient relationship analogous to that of a father/ mother to a child. A father/mother may refuse a child's wishes, may influence a child by a variety of ways - nondisclosure, manipulation, deception, coercion etc., consistent with his/her thinking of what is best for the child. Paternalism can be further divided into soft and hard.

In soft paternalism, the physician acts on grounds of beneficence (and, at times, nonmaleficence) when the patient is nonautonomous or substantially nonautonomous (e.g., cognitive dysfunction due to severe illness, depression, or drug addiction) [27]. Soft paternalism is complicated because of the difficulty in determining whether the patient was nonautonomous at the time of decision-making but is ethically defensible as long as the action is in concordance with what the physician believes to be the patient's values. Hard paternalism is action by a physician, intended to benefit a patient, but contrary to the voluntary decision of an autonomous patient who is fully informed and competent, and is ethically indefensible.

On the other end of the scale of hard paternalism is consumerism, a rare and extreme form of patient autonomy, that holds the view that the physician's role is limited to providing all the medical information and the available choices for interventions and treatments while the fully informed patient selects from the available choices. In this model, the physician's role is constrained, and does not permit the full use of his/her knowledge and skills to benefit the patient, and is tantamount to a form of patient abandonment and therefore is ethically indefensible.

Faced with the contrasting paradigms of beneficence and respect for autonomy and the need to reconcile these to find a common ground, Pellegrino and Thomasma [28] argue that beneficence can be inclusive of patient autonomy as "the best interests of the patients are intimately linked with their preferences" from which "are derived our primary duties to them."

One of the basic and not infrequent reasons for disagreement between physician and patient on treatment issues is their divergent views on goals of treatment. As goals change in the course of disease (e.g., a chronic neurologic condition worsens to the point of needing ventilator support, or a cancer that has become refractory to treatment), it is imperative that the physician communi- 
Table 2. Application of principles of ethics in patient care

\begin{tabular}{|c|c|}
\hline $\begin{array}{l}\text { Beneficence, } \\
\text { nonmaleficence }\end{array}$ & $\begin{array}{l}\text { Clinical assessment } \\
\text { Nature of illness (acute, chronic, reversible, terminal)? } \\
\text { Goals of treatment? } \\
\text { Treatment options and probability of success for each option? } \\
\text { Adverse effects of treatment and does benefit outweigh harm? } \\
\text { Effects of no medical/surgical treatment? } \\
\text { If treated, plans for limiting treatment? Stopping treatment? }\end{array}$ \\
\hline $\begin{array}{l}\text { Beneficence, } \\
\text { nonmaleficence, } \\
\text { respect for autonomy }\end{array}$ & $\begin{array}{l}\text { Quality of life (QOL) } \\
\text { Expected QOL with and without treatment? } \\
\text { Deficits - physical, mental, social - may have after treatment? } \\
\text { Judging QOL of patient who cannot express himself/herself? Who is the judge? } \\
\text { Recognition of possible physician bias in judging QOL? } \\
\text { Rationale to forgo life-sustaining treatment(s)? }\end{array}$ \\
\hline Distributive justice & $\begin{array}{l}\text { External forces and context } \\
\text { Conflicts of interests - does physician benefit financially, professionally by ordering tests, prescribing } \\
\text { medications, seeking consultations? } \\
\text { Research or educational considerations that affect clinical decisions, physician orders? } \\
\text { Conflicts of interests based on religious beliefs? Legal issues? } \\
\text { Conflicts of interests between organizations (clinics, hospitals), 3rd party payers? } \\
\text { Public health and safety issues? } \\
\text { Problems in allocation of scarce resources? }\end{array}$ \\
\hline
\end{tabular}

cates with the patient in clear and straightforward language, without the use of medical jargon, and with the aim of defining the goal(s) of treatment under the changed circumstance. In doing so, the physician should be cognizant of patient factors that compromise decisional capacity, such as anxiety, fear, pain, lack of trust, and different beliefs and values that impair effective communication [29].

The foregoing theoretical discussion on principles of ethics has practical application in clinical practice in all settings. In the resource book for clinicians, Jonsen et al. [30] have elucidated a logical and well accepted model (Table 2), along the lines of the systematic format that practicing physicians have been taught and have practiced for a long time (Chief Complaint, History of Present Illness, Past History, pertinent Family and Social History, Review of Systems, Physical Examination and Laboratory and Imaging studies). This practical approach to problem-solving in ethics involves:

- Clinical assessment (identifying medical problems, treatment options, goals of care)
- Patient (finding and clarifying patient preferences on treatment options and goals of care)

- Quality of life (QOL) (effects of medical problems, interventions and treatments on patient's QOL with awareness of individual biases on what constitutes an acceptable QOL)

- Context (many factors that include family, cultural, spiritual, religious, economic and legal).

Using this model, the physician can identify the principles that are in conflict, ascertain by weighing and balancing what should prevail, and when in doubt, turn to ethics literature and expert opinion.

\section{Illustrative Cases}

There is a wide gamut of clinical patient encounters with ethical issues, and some, especially those involving end-of-life care decisions, are complex. A few cases (Case 1 is modified from resource book [30]) are presented below as they highlight the importance of understanding 
and weighing the ethical principles involved to arrive at an ethically right solution. Case 6 was added during the revision phase of this article as it coincided with the outbreak of Coronavirus Infectious Disease-2019 (COVID-19) that became a pandemic rendering a discussion of its ethical challenges necessary and important.

\section{Case 1}

A 20-year old college student living in the college hostel is brought by a friend to the Emergency Department (ED) because of unrelenting headache and fever. He appeared drowsy but was responsive and had fever $\left(40^{\circ} \mathrm{C}\right)$, and neck rigidity on examination. Lumbar puncture was done, and spinal fluid appeared cloudy and showed increased white cells; Gram stain showed Gram-positive diplococci. Based on the diagnosis of bacterial meningitis, appropriate antibiotics were begun, and hospitalization was instituted. Although initial consent for diagnosis was implicit, and consent for lumbar puncture was explicit, at this point, the patient refuses treatment without giving any reason, and insists to return to his hostel. Even after explanation by the physician as to the seriousness of his diagnosis, and the absolute need for prompt treatment (i.e., danger to life without treatment), the patient is adamant in his refusal.

Comment. Because of this refusal, the medical indications and patient preferences (see Table 2) are at odds. Is it ethically right to treat against his will a patient who is making a choice that has dire consequences (disability, death) who gives no reason for this decision, and in whom a clear determination of mental incapacity cannot be made (although altered mental status may be presumed)? Here the principle of beneficence and principle of autonomy are in conflict. The weighing of factors: (1) patient may not be making a reasoned decision in his best interest because of temporary mental incapacity; and (2) the severity of life-threatening illness and the urgency to treat to save his life supports the decision in favor of beneficence (i.e., to treat).

\section{Case 2}

A 56-year old male lawyer and current cigarette smoker with a pack-a-day habit for more than 30 years, is found to have a solitary right upper lobe pulmonary mass $5 \mathrm{~cm}$ in size on a chest radiograph done as part of an insurance application. The mass has no calcification, and there are no other pulmonary abnormalities. He has no symptoms, and his examination is normal. Tuberculosis skin test is negative, and he has no history of travel to an endemic area of fungal infection. As lung cancer is the most prob- able and significant diagnosis to consider, and early surgical resection provides the best prospects for cure, the physician, in consultation with the thoracic surgeon, recommends bronchoscopic biopsy and subsequent resection. The patient understands the treatment plan, and the significance of not delaying the treatment. However, he refuses, and states that he does not think he has cancer; and is fearful that the surgery would kill him. Even after further explanations on the low mortality of surgery and the importance of removing the mass before it spreads, he continues to refuse treatment.

Comment. Even though the physician's prescribed treatment, that is, removal of the mass that is probably cancer, affords the best chance of cure, and delay in its removal increases its chance of metastases and reaching an incurable stage - the choice by this well informed and mentally competent patient should be respected. Here, autonomy prevails over beneficence. The physician, however, may not abandon the patient and is obligated to offer continued outpatient visits with advice against making decision based on fear, examinations, periodic tests, and encouragement to seek a second opinion.

Case 3

A 71-year-old man with very severe chronic obstructive pulmonary disease (COPD) is admitted to the intensive care unit (ICU) with pneumonia, sepsis, and respiratory failure. He is intubated and mechanically ventilated. For the past 2 years, he has been on continuous oxygen treatment and was short of breath on minimal exertion. In the past 1 year, he had 2 admissions to the ICU; on both occasions he required intubation and mechanical ventilation. Presently, even with multiple antibiotics, intravenous fluid hydration, and vasopressors, his systolic blood pressure remains below $60 \mathrm{~mm} \mathrm{Hg}$, and with high flow oxygen supplementation, his oxygen saturation stays below $80 \%$; his arterial blood $\mathrm{pH}$ is 7.0. His liver enzymes are elevated. He is anuric, and over next $8 \mathrm{~h}$ his creatinine has risen to $5 \mathrm{mg} / \mathrm{dL}$ and continues to rise. He has drifted into a comatose state. The intensivist suggests discontinuation of vasopressors and mechanical ventilation as their continued use is futile. The patient has no advance care directives or a designated health-care proxy.

Comment. The term "futility" is open to different definitions [31] and is often controversial, and therefore, some experts suggest the alternate term, "clinically nonbeneficial interventions" [32]. However, in this case the term futility is appropriate to indicate that there is evidence of physiological futility (multisystem organ failure in the setting of preexisting end stage COPD, and medical 
interventions would not reverse the decline). It is appropriate then to discuss the patient's condition with his family with the goal of discontinuing life-sustaining interventions. These discussions should be done with sensitivity, compassion and empathy. Palliative care should be provided to alleviate his symptoms and to support the family until his death and beyond in their bereavement.

\section{Case 4}

A 67-year old widow, an immigrant from southern India, is living with her son and his family in Wisconsin, USA. She was experiencing nausea, lack of appetite and weight loss for a few months. During the past week, she also had dark yellow urine, and yellow coloration of her skin. She has basic knowledge of English. She was brought to a multi-specialty teaching hospital by her son, who informed the doctor that his mother has "jaundice," and instructed that, if any serious life-threatening disease was found, not to inform her. He asked that all information should come to him, and if there is any cancer not to treat it, since she is older and frail. Investigations in the hospital reveals that she has pancreatic cancer, and chemotherapy, while not likely to cure, would prolong her life.

Comment. In some ancient cultures, authority is given to members of the family (especially senior men) to make decisions that involve other members on marriage, job, and health care. The woman in this case is a dependent of her son, and given this cultural perspective, the son can rightfully claim to have the authority to make health-care decisions for her. Thus, the physician is faced with multiple tasks that may not be consonant. To respect cultural values [33], to directly learn the patient's preferences, to comply with the American norm of full disclosure to the patient, and to refuse the son's demands.

The principle of autonomy provides the patient the option to delegate decision-making authority to another person. Therefore, the appropriate course would be to take the tactful approach of directly informing the patient (with a translator if needed), that the diagnosed disease would require decisions for appropriate treatment. The physician should ascertain whether she would prefer to make these decisions herself, or whether she would prefer all information to be given to her son, and all decisions to be made by him.

\section{Case 5}

A 45-year-old woman had laparotomy and cholecystectomy for abdominal pain and multiple gall stones. Three weeks after discharge from the hospital, she returned with fever, abdominal pain, and tenderness. She was given antibiotics, and as her fever continued, laparotomy and exploration were undertaken; a sponge left behind during the recent cholecystectomy was found. It was removed, the area cleansed, and incision closed. Antibiotics were continued, and she recovered without further incident and was discharged. Should the surgeon inform the patient of his error?

Comment. Truth-telling, a part of patient autonomy is very much applicable in this situation and disclosure to patient is required [34-36]. The mistake caused harm to the patient (morbidity and readmission, and a second surgery and monetary loss). Although the end result remedied the harm, the surgeon is obligated to inform the patient of the error and its consequences and offer an apology. Such errors are always reported to the Operating Room Committees and Surgical Quality Improvement Committees of US Hospitals. Hospital-based risk reduction mechanisms (e.g., Risk Management Department) present in most US hospitals would investigate the incident and come up with specific recommendations to mitigate the error and eliminate them in the future. Many institutions usually make financial settlements to obviate liability litigation (fees and hospital charges waived, and/or monetary compensation made to the patient). Elsewhere, if such mechanisms do not exist, it should be reported to the hospital. Acknowledgment from the hospital, apologies from the institution and compensation for the patient are called for. Whether in US or elsewhere, a malpractice suit is very possible in this situation, but a climate of honesty substantially reduces the threat of legal claims as most patients trust their physicians and are not vindictive.

\section{Case(s) 6}

The following scenario is at a city hospital during the peak of the COVID-19 pandemic: A 74-year-old woman, residing in an assisted living facility, is brought to the ED with shortness of breath and malaise. Over the past 4 days she had been experiencing dry cough, lack of appetite, and tiredness; 2 days earlier, she stopped eating and started having a low-grade fever. A test for COVID-19 undertaken by the assisted living facility was returned positive on the morning of the ED visit.

She, a retired nurse, is a widow; both of her grown children live out-of-state. She has had hypertension for many years, controlled with daily medications. Following 2 strokes, she was moved to an assisted living facility 3 years ago. She recovered most of her functions after the strokes and required help only for bathing and dressing. She is able to answer questions appropriately but haltingly, because of respiratory distress. She has tachypnea (34/min), 
tachycardia (120/min), temperature of $101^{\circ} \mathrm{F}, \mathrm{BP} 100 / 60$ and $90 \% \mathrm{O}_{2}$ saturation (on supplemental $\mathrm{O}_{2}$ of $4 \mathrm{~L} / \mathrm{min}$ ). She has dry mouth and tongue and rhonchi on lung auscultation. Her respiratory rate is increasing on observation and she is visibly tiring.

Another patient is now brought in by ambulance; this is a 22-year-old man living in an apartment and has had symptoms of "flu" for a week. Because of the pandemic, he was observing the recommended self-distancing, and had no known exposure to coronavirus. He used saline gargles, acetaminophen, and cough syrup to alleviate his sore throat, cough, and fever. In the past 2 days, his symptoms worsened, and he drove himself to a virus testing station and got tested for COVID-19; he was told that he would be notified of the results. He returned to his apartment and after a sleepless night with fever, sweats, and persistent cough, he woke up and felt drained of all strength. The test result confirmed COVID-19. He then called for an ambulance.

He has been previously healthy. He is a non-smoker and uses alcohol rarely. He is a second-year medical student. He is single, and his parents and sibling live hundreds of miles away.

On examination, he has marked tachypnea ( $>40 / \mathrm{min})$, shallow breathing, heart rate of $128 / \mathrm{min}$, temperature of $103^{\circ} \mathrm{F}$ and $\mathrm{O}_{2}$ saturation of 88 on pulse oximetry. He appears drowsy and is slow to respond to questions. He is propped up to a sitting position as it is uncomfortable for him to be supine. Accessory muscles of neck and intercostals are contracting with each breath, and on auscultation, he has basilar crackles and scattered rhonchi. His $\mathrm{O}_{2}$ saturation drops to 85 and he is in respiratory distress despite nebulized bronchodilator treatment.

Both of these patients are in respiratory failure, clinically and confirmed by arterial blood gases, and are in urgent need of intubation and mechanical ventilation. However, only one ventilator is available; who gets it?

Comment. The decision to allocate a scarce and potentially life-saving equipment (ventilator) is very difficult as it directly addresses the question "Who shall live when not everyone can live? [5]. This decision cannot be emotiondriven or arbitrary; nor should it be based on a person's wealth or social standing. Priorities need to be established ethically and must be applied consistently in the same institution and ideally throughout the state and the country. The general social norm to treat all equally or to treat on a first come, first saved basis is not the appropriate choice here. There is a consensus among clinical ethics scholars, that in this situation, maximizing benefits is the dominant value in making a decision [37]. Maximizing benefits can

Ethics in Clinical Practice be viewed in 2 different ways; in lives saved or in life-years saved; they differ in that the first is non-utilitarian while the second is utilitarian. A subordinate consideration is giving priority to patients who have a better chance of survival and a reasonable life expectancy. The other 2 considerations are promoting and rewarding instrumental value (benefit to others) and the acuity of illness. Health-care workers (physicians, nurses, therapists etc.) and research participants have instrumental value as their work benefits others; among them those actively contributing are of more value than those who have made their contributions. The need to prioritize the sickest and the youngest is also a recognized value when these are aligned with the dominant value of maximizing benefits. In the context of COVID-19 pandemic, Emanuel et al. [37] weighed and analyzed these values and offered some recommendations. Some ethics scholars opine that in times of a pandemic, the burden of making a decision as to who gets a ventilator and who does not (often a life or death choice) should not be on the front-line physicians, as it may cause a severe and life-long emotional toll on them $[35,36]$. The toll can be severe for nurses and other front-line health-care providers as well. As a safeguard, they propose that the decision should rest on a select committee that excludes doctors, nurses and others who are caring for the patient(s) under consideration [38].

Both patients described in the case summaries have comparable acuity of illness and both are in need of mechanical ventilator support. However, in the dominant value of maximizing benefits the two patients differ; in terms of life-years saved, the second patient (22-year-old man) is ahead as his life expectancy is longer. Additionally, he is more likely than the older woman, to survive mechanical ventilation, infection, and possible complications. Another supporting factor in favor of the second patient is his potential instrumental value (benefit to others) as a future physician.

Unlike the other illustrative cases, the scenario of these 2 cases, does not lend itself to a peaceful and fully satisfactory resolution. The fairness of allocating a scarce and potentially life-saving resource based on maximizing benefits and preference to instrumental value (benefit to others) is open to question. The American College of Physicians has stated that allocation decisions during resource scarcity should be made "based on patient need, prognosis (determined by objective scientific measure and informed clinical judgment) and effectiveness (i.e., likelihood that the therapy will help the patient to recover), ... to maximize the number of patients who will recover" [39]. 
Fig. 1. Integrated model of patient care.

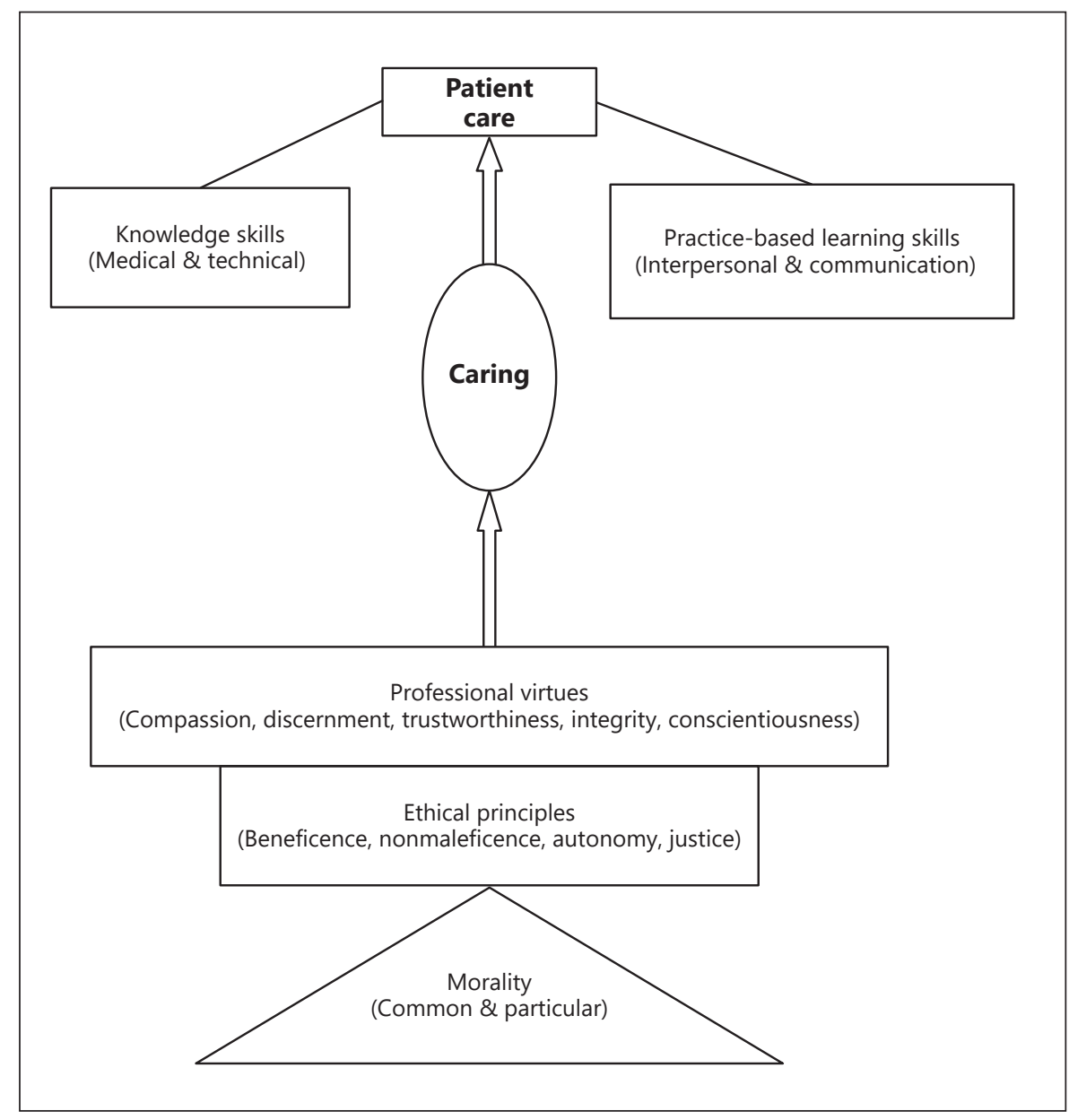

\section{Conclusion}

This review has covered basics of ethics founded on morality and ethical principles with illustrative examples. In the following segment, professionalism is defined, its alignment with ethics depicted, and virtues desired of a physician (inclusive term for medical doctor regardless of type of practice) are elucidated. It concludes with my vision of an integrated model for patient care.

The core of professionalism is a therapeutic relationship built on competent and compassionate care by a physician that meets the expectation and benefits a patient. In this relationship, which is rooted in the ethical principles of beneficence and nonmaleficence, the physician fulfills the elements shown in Table 3. Professionalism "demands placing the interest of patients above those of the physician, setting and maintaining standards of competence and integrity, and providing expert advice to society on matters of health" $[26,40]$.
Table 3. Physicians obligations

- Cure of disease when possible

- Maintenance or improvement of functional status and quality of life (relief of symptoms and suffering)

- Promotion of health and prevention of disease

- Prevention of untimely death

- Education and counseling of patients (condition and prognosis)

- Avoidance of harm to the patient in the course of care

- Providing relief and support near time of death (end-of-life care)

Drawing on several decades of experience in teaching and mentoring, I envisage physicians with qualities of both "heart" and "head." Ethical and humanistic values shape the former, while knowledge (e.g., by study, research, practice) and technical skills (e.g., medical and 
surgical procedures) form the latter. Figure 1 is a representation of this model. Morality that forms the base of the model and ethical principles that rest on it were previously explained. Virtues are linked, some more tightly than others, to the principles of ethics. Compassion, a prelude to caring, presupposes sympathy, is expressed in beneficence. Discernment is especially valuable in decision-making when principles of ethics collide. Trustworthiness leads to trust, and is a needed virtue when patients, at their most vulnerable time, place themselves in the hands of physicians. Integrity involves the coherent integration of emotions, knowledge and aspirations while maintaining moral values. Physicians need both professional integrity and personal integrity, as the former may not cover all scenarios (e.g., prescribing ineffective drugs or expensive drugs when effective inexpensive drugs are available, performing invasive treatments or experimental research modalities without fully informed consent, any situation where personal monetary gain is placed over patient's welfare). Conscientiousness is required to determine what is right by critical reflection on good versus bad, better versus good, logical versus emotional, and right versus wrong.

In my conceptualized model of patient care (Fig. 1), medical knowledge, skills to apply that knowledge, technical skills, practice-based learning, and communication skills are partnered with ethical principles and professional virtues. The virtues of compassion, discernment, trustworthiness, integrity, and conscientiousness are the necessary building blocks for the virtue of caring. Caring is the defining virtue for all healthcare professions. In all interactions with patients, besides the technical expertise of a physician, the human element of caring (one human to another) is needed. In different situations, caring can be expressed verbally and non-verbally (e.g., the manner of communication with both physician and patient closely seated, and with unhurried, softly spoken words); a gentle touch especially when conveying "bad news"; a firmer touch or grip to convey reassurance to a patient facing a difficult treatment choice; to hold the hand of a patient dying alone). Thus, "caring" is in the center of the depicted integrated model, and as Peabody succinctly expressed it nearly a hundred years ago, "The secret of the care of the patient is caring for the patient" [41].

\section{Conflict of Interest Statement}

The author declares that he has no conflicts of interest.

\section{References}

1 Singer PA, Pellegrino ED, Siegler M. Clinical ethics revisited. BMC Med Ethics. 2001;2(1):E1.

2 Carrese JA, Sugarman J. The inescapable relevance of bioethics for the practicing clinician. Chest. 2006 Dec;130(6):1864-72.

3 Sulmasy DP, Geller G, Levine DM, Faden RR. A randomized trial of ethics education for medical house officers. J Med Ethics. 1993 Sep;19(3):157-63.

4 Self DJ, Olivarez M, Baldwin DC Jr. Clarifying the relationship of medical education and moral development. Acad Med. 1998 May; 73(5):517-20.

5 Beauchamp TL, Childress JF. Principles of bioethics. 7th ed. Oxford University Press; 2013.

6 Berkman ND, Wynia MK, Churchill LR Gaps, conflicts, and consensus in the ethics statements of professional associations, medical groups, and health plans. J Med Ethics. 2004 Aug;30(4):395-401.

7 Beauchamp TL, Childress JF. Principles of biomedical ethics. New York (NY): Oxford University Press; 2009. pp. 162-4.

8 Mularski RA, Puntillo K, Varkey B, Erstad BL, Grap MJ, Gilbert HC, et al. Pain management within the palliative and end-of-life care experience in the ICU. Chest. 2009 May; 135(5): 1360-9.
9 Guyer P. Kant on the theory and practice of autonomy. Soc Philos Policy. 2003;20(2):7098.

10 Cardozo B. Basic right to consent to medical care - Schlendorff vs the Society of the New York Hospital, 211 NY 125105 NE 921914 LEXUS 1028 (1914).

11 Grisso T, Appelbaum PS. Assessing competence to consent to treatment: A guide to physicians and other health professionals. New York: Oxford University Press; 1998. p. 11.

12 Mackenzie CM, Stoljar N. Relational autonomy: Feminist perspectives on autonomy, agency, and the social self. New York: Oxford University Press; 2000.

13 Blackhall LJ, Murphy ST, Frank G, Michel V, Azen S. Ethnicity and attitudes toward patient autonomy. JAMA. 1995 Sep;274(10):820-5.

14 Levine RJ. Informed consent: Some challenges to the universal validity of the western model. In: Vaughn L, editor. Bioethics: Principles, issues and cases. New York (NY): Oxford University Press; 2010. pp. 183-8.

15 Angell M. Ethical imperialism? Ethics in international collaborative clinical research. N Engl J Med. 1988 Oct;319(16):1081-3.

16 Appelbaum PS, Grisso T. Assessing patients' capacities to consent to treatment. N Engl J Med. 1988 Dec;319(25):1635-8.
17 Davis JK. The concept of precedent autonomy. Bioethics. 2002 Apr;16(2):114-33.

18 Sulmasy DP, Snyder L. Substituted interests and best judgments: an integrated model of surrogate decision making. JAMA. 2010 Nov; 304(17):1946-7.

19 Oken D. What to tell cancer patients. A study of medical attitudes. JAMA. 1961 Apr; 175(13):1120-8.

20 Novack DH, Plumer R, Smith RL, Ochitill H, Morrow GR, Bennett JM. Changes in physicians' attitudes toward telling the cancer patient. JAMA. 1979 Mar;241(9):897-900.

21 Rayson D. A piece of my mind. Lisa's stories. JAMA. 1999 Nov;282(17):1605-6.

22 Fallowfield LJ, Jenkins VA, Beveridge HA. Truth may hurt but deceit hurts more: communication in palliative care. Palliat Med. 2002 Jul;16(4):297-303.

23 Surbone A. Truth telling to the patient. JAMA. 1992 Oct;268(13):1661-2.

24 Weiss BD. Confidentiality expectations of patients, physicians, and medical students. JAMA. 1982 May;247(19):2695-7.

25 Fleishacker S. A short history of distributive justice. Cambridge (MA): Harvard University Press; 2005. 
26 ABIM Foundation. American Board of Internal MedicineACP-ASIM Foundation. American College of Physicians-American Society of Internal MedicineEuropean Federation of Internal Medicine. Medical professionalism in the new millennium: a physician charter. Ann Intern Med. 2002 Feb;136(3):243-6.

27 Tonelli MR, Misak CJ. Compromised autonomy and the seriously ill patient. Chest. 2010 Apr;137(4):926-31.

28 Pellegrino E, Thomasma D. For the patient's good: The restoration of beneficence in health care. New York: Oxford University Press; 1988. p. 29.

29 Dubler NN, Liebman CB. Bioethics Mediation: A Guide to Shaping Shared Solutions. New York, NY: United Hospital Fund of New York; 2004.

30 Jonsen AR, Siegler M, Winslade WJ. Ethics: A practical approach to ethical decisions in clinical medicine. McGraw Hill; 2015, 8th edition.

31 Pope TM. Legal briefing: futile or non-beneficial treatment. J Clin Ethics. 2011;22(3): 277-96.
32 Schneiderman LJ, Jecker NS, Jonsen AR. Medical futility: its meaning and ethical implications. Ann Intern Med. 1990 Jun;112(12): 949-54.

33 Boyle JM, Novak D. Religious and cultural perspectives in bioethics. In: Singer PA, Viens AM, editors. The Cambridge Textbook of Bioethics. New York (NY): Cambridge University Press; 2009.

34 Eaves-Leanos A, Dunn EJ. Open disclosure of adverse events: transparency and safety in health care. Surg Clin North Am. 2012 Feb; 92(1):163-77.

35 Gallagher TH, Studdert D, Levinson W. Disclosing harmful medical errors to patients. N Engl J Med. 2007 Jun;356(26):2713-9.

36 Chapter 34. In: Lo B. Disclosing errors. Resolving Ethical Dilemmas: A Guide for Clinicians. Philadelphia (PA): Lippincott Williams \& Wilkins; 2013.
37 Emanuel EJ, Persad G, Upshur R, Thome B, Parker M, Glickman A, et al. Fair allocation of scarce medical resources in the time of Covid-19. N Engl J Med. 2020 May;382(21):204955.

38 Truog RD, Mitchell C, Daley GQ. The toughest triage-allocating ventilators in a pandemic. N Engl J Med. 2020 May;382(21):1973-5.

39 American College of Physicians. Non-discrimination in the stewardship and allocation of resources during health system catastrophes including COVID-19. Available from: www.acponline.org/acp_policy/policies/acp_ policy_on_non-discriminationin_the_stewardship_of_healthcare_resources_in_ health_system_catastrophes_including_covid-19_2020.pdf. Accessed on April 5, 2020.

40 Dugdale LS, Siegler M, Rubin DT. Medical professionalism and the doctor-patient relationship. Perspect Biol Med. 2008;51(4):54753.

41 Peabody FW. The care of the patient. JAMA. 1927;88(12):877-82. 